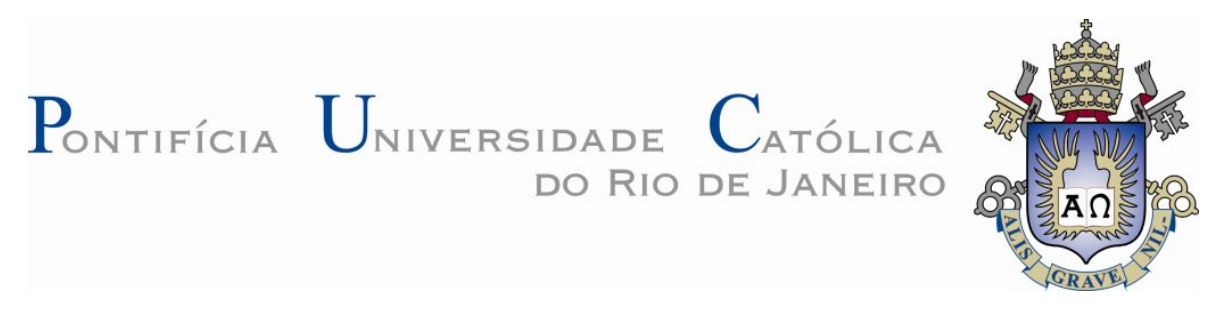

Roxana Olarte Enciso

Comportamento de Pilares Esbeltos de Concreto de Alta Resistência Sujeitos à Flexão Composta Reta

Dissertação de Mestrado

Dissertação apresentada ao Programa de Pósgraduação em Engenharia Civil da PUC-Rio como requisito parcial para obtenção do título de Mestre em Engenharia Civil.

Orientador: Giuseppe Barbosa Guimarães

Rio de Janeiro

Julho de 2010 


\section{Comportamento de Pilares Esbeltos de Concreto de Alta Resistência Sujeitos à Flexão Composta Reta}

Dissertação apresentada como requisito parcial para obtenção do grau de Mestre pelo Programa de Pós-Graduação em Engenharia Civil da PUCRio. Aprovada pela Comissão Examinadora abaixo assinada.

Prof. Giuseppe Barbosa Guimarães

Orientador

Departamento de Engenharia Civil - PUC-Rio

Profa. Marta de Souza Lima Velasco

Departamento de Engenharia Civil - PUC-Rio

Profa. Claudia Maria de Oliveira Campos

Universidade Federal Fluminense

Prof. José Márcio Fonseca Calixto

Universidade Federal de Minas Gerais

Prof. José Eugenio Leal

Coordenador Setorial do Centro

Técnico Científico - PUC-Rio

Rio de Janeiro, 22 de julho de 2010 
Todos os direitos reservados. É proibida a reprodução total ou parcial do trabalho sem autorização da universidade, do autor e do orientador.

\section{Roxana Olarte Enciso}

Graduou-se em Engenharia Civil da UNSAAC (Universidad Nacional de San Antonio Abad del Cusco Peru), em 2005. Em 2008 iniciou o curso de Mestrado em Engenharia Civil na PUC-Rio, na area de Estruturas, atuando na linha de pesquisa de Concreto Armado.

Ficha Catalográfica

Olarte Enciso, Roxana

Comportamento de pilares esbeltos de concreto de alta resistência sujeitos à flexão composta reta/ Roxana Olarte Enciso; orientador: Giuseppe Barbosa Guimarães. - 2010.

88 f. : il. (color) ; $30 \mathrm{~cm}$

Dissertação (Mestrado) - Pontifícia Universidade Católica do Rio de Janeiro, Departamento de Engenharia Civil, Rio de Janeiro, 2010.

Inclui bibliografia

1. Engenharia Civil - Teses. 2. Pilares esbeltos. 3. Concreto de alta resistência. 4. Flexo compressão. I. Guimarães, Giuseppe Barbosa. II. Pontifícia Universidade Católica do Rio de Janeiro. Departamento de Engenharia Civil. III. Título. 
Aos meus pais, pelo inesgotável amor, apoio e estímulo os quais me impulsionam sempre a alcançar meus objetivos.

Às minhas irmãs, por sua amizade incondicional.

Aos meus sobrinhos, que com seus sorrisos alegram cada um de meus dias. 


\section{Agradecimentos}

Agradeço em primeiro lugar a Deus por ter me concedido a vida e a família que tenho, por todas as bençãos recebidas e por sua presença em todos os meus dias.

Aos meus pais: Ramiro e Elisabeth pelo inesgotável amor, apoio e estímulo que sempre me deram, com os quais me impulsionaram a alcançar meus objetivos.

Às minhas Irmãs Laura e Nadia, por seu exemplo e amizade incondicional demonstrado ao longo de todos esses anos.

Aos meus sobrinhos: Marieli, José Ramiro, Valeria e Alejandro, que com seus sorrisos alegram cada um de meus dias.

Ao meu orientador, professor Giuseppe Barbosa Guimarães, pela oportunidade, paciência e orientação recebida ao longo da realização deste trabalho.

Aos professores do Departamento de Engenharia Civil da PUC-Rio, pelos ensinamentos transmitidos.

Aos amigos conquistados durante esse período, Alejandra, Lydice, Liliana, Liset, Fernando, Elvis, Gino e tantos outros que não citei, por tornarem esta jornada mais agradável.

Aos funcionários do Laboratório de Estruturas, Euclídes, José Nilson, Evandro e Haroldo que foram essenciais na realização dos ensaios experimentais.

À Pontifícia Universidade Católica do Rio de Janeiro pela oportunidade de fazer o mestrado.

Ao CNPq pelo apoio financeiro fornecido, sem o qual este trabalho simplesmente não teria sido possível. 


\section{Resumo}

Olarte Enciso, Roxana; Guimarães, Giuseppe Barbosa. Comportamento de Pilares Esbeltos de Concreto de Alta Resistência Sujeitos à Flexão Composta Reta. Rio de Janeiro, 2010. 88p. Dissertação de Mestrado Departamento de Engenharia Civil, Pontifícia Universidade Católica do Rio de Janeiro.

Este trabalho apresenta um estudo experimental do comportamento de pilares esbeltos de alta resistência submetidos à flexão composta reta. Foram ensaiados oito pilares divididos em duas séries, sendo uma série com concreto de $40 \mathrm{MPa}$ e a outra com concreto de $80 \mathrm{MPa}$ aos vinte e oito dias. Todos os pilares tinham seção transversal de $15 \times 25 \mathrm{~cm}$ e altura de $300 \mathrm{~cm}$. Em cada série, a variável foi a taxa de armadura longitudinal que assumiu quatro valores diferentes. O objetivo foi verificar os valores da excentricidade de segunda ordem que devem ser considerados no dimensionamento de pilares esbeltos de concreto de alta resistência. Os resultados dos ensaios foram comparados com os resultados teóricos obtidos pelos modelos da curvatura aproximada e da rigidez aproximada que constam na NBR6118:2003. Essa comparação mostrou uma boa concordância entre os resultados experimentais e teóricos

\section{Palavras-chave}

Pilares esbeltos; concreto de alta resistência; flexo compressão. 


\section{Abstract}

Olarte Enciso, Roxana; Guimarães, Giuseppe Barbosa (Advisor). Behavior of Slender High Strength Concrete Columns Subjected to Axial Load and Bending about One Axis. Rio de Janeiro, 2010. 88p. MSc. Dissertation-Departamento de Engenharia Civil, Pontifícia Universidade Católica do Rio de Janeiro.

This work presents an experimental study of the behavior of slender high strength concrete columns under uniaxial eccentric compression loads. Eight columns were tested, divided into two series, one series with concrete of $40 \mathrm{MPa}$ and the other with concrete of $80 \mathrm{MPa}$ at twenty eight days. All columns had a cross-section of $15 \times 25 \mathrm{~cm}$ and height of $300 \mathrm{~cm}$. In each series, the variable was the longitudinal reinforcement ratio which assumed four different values. The objective was to verify the values of the eccentricity of second order that should be taken into account in the design of slender high strength concrete columns. The experimental results were compared with theoretical results obtained by the models of the approximated curvature and approximated stiffnes methods prescribed in the NBR6118:2003 code. This comparison showed a good agreement between the experimental and theoretical results.

\section{Keywords}

Slender columns; high strength concrete; eccentric compression. 


\section{Sumário}

1. Introdução 14

1.1. Considerações iniciais 14

1.2. Objetivo 14

1.3. Estrutura do trabalho 15

2. Revisão Bibliográfica 16

2.1. Considerações iniciais 16

2.2. Pilares de concreto armado 16

2.3. Situações básicas de projeto 16

2.3.1. Efeitos locais de $1^{\text {a }}$ ordem 18

2.3.2. Efeitos locais de $2^{\mathrm{a}}$ ordem 18

2.4. Excentricidade 19

2.4.1. Excentricidade de $1^{\text {a }}$ ordem 19

2.4.2. Excentricidade acidental 19

2.4.3. Excentricidade de $2^{\mathrm{a}}$ ordem 20

2.5. Índice de esbeltez $\quad 21$

2.5.1. Esbeltez limite $\lambda_{1}$

2.5.2. Classificação quanto à esbeltez 23

2.6. Determinação dos efeitos locais de $2^{\mathrm{a}}$ ordem 24

2.6.1. Método geral 24

2.6.2. Métodos aproximados $\quad 24$

2.6.2.1. Método do pilar-padrão com curvatura aproximada 24

2.6.2.2. Método do pilar-padrão com rigidez $k$ aproximada 25

2.6.2.3. Método do pilar-padrão acoplado a diagramas $M, N, 1 / r \quad 26$

2.7. Estado limite último $\quad 27$

2.7.1. Ruína por ruptura $\quad 27$

$\begin{array}{ll}\text { 2.7.2. Instabilidade do equilíbrio } & 27\end{array}$

2.8. Pesquisas sobre pilares de concreto armado 28

2.8.1. LLOYD e RANGAN (1996) 28

2.8.2. LEE e SON (2000) 32 
3. Programa Experimental 35

3.1. Considerações Iniciais 35

3.2. Materiais Utilizados $\quad 35$

3.2.1. Cimento 35

3.2.2. Silica ativa $\quad 35$

3.2.3. Aditivo hiperplastificante 36

3.2.4. Agregado miúdo 36

3.2.5. Agregado graúdo 37

3,2.6. Água $\quad 37$

3.3. Concreto 38

3.4. Aço 48

3.5. Programa experimental $\quad 49$

3.5.1. Pilares ensaiados $\quad 49$

3.5.2. Fôrmas 55

3.5.3. Concretagem, adensamento e cura 56

3.5.4. Instrumentação 56

3.5.5. Procedimento de ensaio 58

4. Apresentação e análise dos resultados $\quad 60$

4.1. Modos de ruptura 60

4.3. Curvas força-deformação 66

4.4. Curvas carga-deslocamento 72

$\begin{array}{ll}\text { 4.4.1. Pilares da série I } & 73\end{array}$

4.4.2. Pilares da série II 74

4.5. Comparação entre resultados experimentais e teóricos 76

4.5.1. Excentricidades de $2^{\mathrm{a}}$ ordem 76

4.5.2 Resistência dos pilares 80

5. Conclusões e sugestões para trabalhos futuros 84

5.1. Conclusões 84

5.2. Sugestões para trabalhos futuros 85

6. Referências Bibliográficas 86 


\section{Lista de figuras}

Figura 2.1 - Arranjo estrutural e situação de projeto dos pilares intermediários (BASTOS, 2005)

Figura 2.2 - Arranjo estrutural e situação de projeto dos pilares de extremidade (BASTOS, 2005)

Figura 2.3 - Arranjo estrutural e situação de projeto dos pilares de canto (BASTOS, 2005)

Figura 2.4 - Casos possíveis de excentricidade de $1^{\text {a }}$ ordem (BASTOS, 2005)

Figura 2.5 - Casos de possíveis de imperfeições geométricas (GUIMARÃES, 2009)

Figura 2.6 - Casos possíveis de excentricidade de $2^{\mathrm{a}}$ ordem (MELGES, 2007)

Figura 2.7 - Comprimento de flambagem (BASTOS, 2005)

Figura 2.8 - Curva carga - deslocamento, ruína por ruptura

Figura 2.9 - Curva carga - deslocamento, instabilidade do equilíbrio 28

Figura 2.10 - Detalhes dos pilares ensaiados (LLOYD e RANGAN, 1996) 29

Figura 2.11 - Curvas força-deslocamento na região central do pilar (LLOYD e RANGAN, 1996)

Figura 2.12 - Detalhes dos pilares ensaiados (LEE e SON, 2000)

Figura 3.1 - Ensaios de caracterização do concreto

Figura 3.2 - Diagrama tensão-deformação do corpo de prova do Pilar C40-1.3

Figura 3.3 - Diagrama tensão-deformação do corpo de prova do Pilar

C40-2.1

Figura 3.4 - Diagrama tensão-deformação do corpo de prova do Pilar C40-3.2

Figura 3.5 - Diagrama tensão-deformação do corpo de prova do Pilar C40-4.3

Figura 3.6 - Diagrama tensão-deformação do corpo de prova do Pilar C80-1.3 
Figura 3.7 - Diagrama tensão-deformação do corpo de prova do Pilar C80-2.1

Figura 3.8 - Diagrama tensão-deformação do corpo de prova do Pilar C80-3.2

Figura 3.9 - Diagrama tensão-deformação do corpo de prova do Pilar C80-4.3

Figura 3.10 - Ensaio de à tração das barras de aço

Figura 3.11 - Diagrama tensão-deformação da barra $\phi 10 \mathrm{~mm}$

Figura 3.12 - Diagrama tensão-deformação da barra ф 16 mm

Figura 3.13 - Armadura de fretagem

Figura 3.14 - Detalhamento das armaduras dos pilares C40-1.3 e C80-1.3

Figura 3.15 - Detalhamento das armaduras dos pilares C40-2.1 e C80-2.1 52

Figura 3.16 - Detalhamento das armaduras dos pilares C40-3.2 e C80-3.2 53

Figura 3.17 - Detalhamento das armaduras dos pilares C40-4.3 e C80-4.3 54

Figura 3.18 - Detalhes da forma metálica 55

Figura 3.19 - Disposição das armaduras na fôrma metálica 55

Figura 3.20 - Concretagem do pilar

Figura 3.21 - Posicionamento dos extensômetros elétricos no aço e concreto na seção localizada a meia altura do pilar

Figura 3.22 - Extensômetros elétricos colados no aço e no concreto

Figura 3.23 - Esquema do equipamento de ensaio e montagem do pilar 58

Figura 3.24 - Posicionamento do pilar - Excentricidade inicial 59

Figura 4.1 - Ensaio do pilar C40-1.3 61

Figura 4.2 - Ensaio do pilar C40-2.1 61

Figura 4.3 - Ensaio do pilar C40-3.2 62

Figura 4.4 - Ensaio do pilar C40-4.3 62

Figura 4.5 - Ensaio do pilar C80-1.3 63

Figura 4.6 - Ensaio do pilar C80-2.1 63

Figura 4.7 - Ensaio do pilar C80-3.2 64

Figura 4.8 - Ensaio do pilar C80-4.3 64

Figura 4.9 - Vista da ruptura dos pilares da série I 65

Figura 4.10 - Vista da ruptura dos pilares da série II 66

Figura 4.11 - Curvas força - deformação no pilar C40 - $1.3 \quad 67$

Figura 4.12 - Curvas força - deformação no pilar C40 - 2.1 67

Figura 4.13 - Curvas força - deformação no pilar C40 - 3.2

Figura 4.14 - Curvas força - deformação no pilar C40 - 4.3 68

Figura 4.15 - Curvas força - deformação no pilar C80 - 1.3 
Figura 4.16 - Curvas força - deformação no pilar C80 - 2.1 69

Figura 4.17 - Curvas força - deformação no pilar C80 - 3.2

Figura 4.18 - Curvas força - deformação no pilar C80 - $4.3 \quad 70$

Figura 4.19 - Distribuição de deformações na seção média dos pilares da série I

Figura 4.20 - Distribuição de deformações na seção média dos pilares da série II

Figura 4.21 - Deslocamento transversal no pilar 73

Figura 4.22 - Curvas força-deslocamento na região central da série I 74

Figura 4.23 - Curvas força-deslocamento na região central da série II 75

Figura 4.24 - Comparação entre as excentricidades de $2^{\mathrm{a}}$ ordem $\quad 77$

Figura 4.25 - Comparação entre as excentricidades totais 77

Figura 4.26 - Comparação entre as excentricidades de $2^{\mathrm{a}}$ ordem (LLOYD

e RANGAN, 1996) 78

Figura 4.27 - Comparação entre as excentricidades totais (LLOYD e RANGAN, 1996) 78

Figura 4.28 - Comparação entre as excentricidades de $2^{\mathrm{a}}$ ordem (LEE e SON, 2000) $\quad 79$

Figura 4.29 - Comparação entre as excentricidades totais (LEE e SON, 2000)

Figura 4.30 - Diagrama tensão - deformação do concreto 80

Figura 4.31 - Diagrama de interação $v-\mu$ e dados experimentais da série I 82

Figura 4.32 - Diagrama de interação $v-\mu$ e dados experimentais da série II 83 


\section{Lista de tabelas}

Tabela 2.1 - Resultados dos ensaios (LLOYD e RANGAN, 1996) 31

Tabela 2.2 - Resultados dos ensaios (LEE e SON, 2000) 34

Tabela 3.1 - Análise granulométrica do agregado miúdo 36

Tabela 3.2 - Análise granulométrica do agregado graúdo 37

Tabela 3.3 - Traço dos concretos utilizados para $1 \mathrm{~m}^{3} \quad 38$

Tabela 3.4 - Resistência à compressão do concreto 39

Tabela 3.5 - Propriedades mecânicas do concreto 39

Tabela 3.6 - Valores do módulo de elasticidade do concreto do Pilar

C40-1.3 40

Tabela 3.7 - Valores do módulo de elasticidade do concreto do Pilar

C40-2.1

Tabela 3.8 - Valores do módulo de elasticidade do concreto do Pilar C40-3.2

Tabela 3.9 - Valores do módulo de elasticidade do concreto do Pilar C40-4.3

Tabela 3.10 - Valores do módulo de elasticidade do concreto do Pilar C80-1.3

Tabela 3.11 - Valores do módulo de elasticidade do concreto do Pilar C80-2.1

Tabela 3.12 - Valores do módulo de elasticidade do concreto do Pilar C80-3.2

Tabela 3.13 - Valores do módulo de elasticidade do concreto do Pilar C80-4.3

Tabela 3.14 - Propriedades mecânicas das barras de aço 48

Tabela 3.15 - Características dos pilares $\quad 50$

Tabela 4.1 - Resultados gerais dos pilares ensaiados $\quad 60$

Tabela 4.2 - Resultados adimensionais dos pilares ensaiados 81 